ORIGINAL PAPER

\title{
DEgENERATION AND CALCIFICATION OF THE CERVICAL ENDPLATE IS CONNECTED WITH DECREASED EXPRESSION OF ANK, ENPP-1, OPN AND TGF- $\beta 1$ IN THE INTERVERTEBRAL DISC
}

\author{
Krzysztof A. Tomaszewski ${ }^{1}$, Dariusz Adamek ${ }^{2}$, Artur Pasternak ${ }^{1}$, Roman Glowacki ${ }^{3}$, \\ Romana Tomaszewska ${ }^{2}$, Jerzy A. Walocha ${ }^{1}$
}

\begin{abstract}
${ }^{1}$ Department of Anatomy, Jagiellonian University Medical College, Krakow, Poland ${ }^{2}$ Department of Pathology, Jagiellonian University Medical College, Krakow, Poland

${ }^{3}$ Department of Otorhinolaryngology, Rydygier Specialist Hospital, Krakow, Poland
\end{abstract}

\begin{abstract}
The aim of this study was to clarify the relationship between the expression of ALP, ANK, ENPP-1, OPN and TGF- $\beta 1$ in the intervertebral disc (IVD), and cervical vertebral endplate calcification and degeneration. Sixty cervical IVDs were excised from 30 human cadavers. Each cadaver was assessed macroscopically for degeneration (Thompson's classification), and then underwent histological processing, regular staining (hematoxylin and eosin, Masson-Goldner trichrome and alcian blue-PAS), immunohistochemistry (ALP, ANK, ENPP-1, OPN and TGF- $\beta 1$ ), microscopic degeneration grading (Boos classification), and assessment of endplate calcification. The mean age \pm SD of the cadavers was $51.4 \pm 19.5$. The percentage of endplate calcification significantly correlated with the degree of endplate and IVD degeneration graded using Boos's score (both $\mathrm{r}=0.91 ; \mathrm{p}<0.0001$ ). The intensity and number of stained cells per FOV markedly decreased, for ANK, ENPP-1, and TGF- $\beta 1$, with the grade of IVD degeneration, regardless of the analyzed IVD region. This was not true only for ALP, which demonstrated an increasing trend corresponding to the degree of IVD degeneration. The expression of OPN was low throughout all analyzed regions, regardless of the degree of degeneration. Modulating the expression of the abovementioned proteins, especially ANK and TGF- $\beta 1$, may be a new way to prevent degeneration and calcification of the IVD.
\end{abstract}

Key words: ANK, calcification, cervical intervertebral disc, degeneration, endplate.

\section{Introduction}

In the most recent Global Burden of Disease Study [1] low back pain (LBP) was found to be the biggest contributor to Years Lived with Disability (YLDs). Low back pain is the most common form of chronic pain, costing the UK's economy over 6.6 billion pounds in 1998 [2]. The prevalence rates range from $12 \%$ to $35 \%$, with around $10 \%$ of patients becoming chronically disabled [3].
Back pain has a strong association with the intervertebral disc (IVD) [4]. Discs degenerate far earlier than other musculoskeletal tissues, and the first findings of degeneration in the lumbar discs are seen at 11-16 years of age [5]. The process of degeneration increases steeply with age, especially in males around $10 \%$ of 50 -year-olds and $60 \%$ of 70 -year-olds have severely degenerate IVDs $[4,5]$.

Although the complex and dynamic relationships between disc degeneration and sclerosis of the ver- 
tebral endplate are well recognized, they are poorly understood. Intervertebral disc degenerative disease is known to be caused by a series of factors including ageing, biochemical changes (loss of proteoglycan, collagen fibers and increased enzymatic activity), genetics, mechanical loading and injury, as well as impaired disc nutrition [4]. The IVD is the largest avascular structure in the human body [6], and the main way for it to receive nutrients is through diffusion from the capillary buds penetrating the vertebral endplate [7]. Endplate calcification, through a decrease in its permeability, may lead to a fall in nutrient delivery to the cells of the IVD [7], and through that to its degeneration and mechanical failure [8].

The $A N K H$ gene is the human homologue of the gene responsible for progressive ankylosis in a naturally occurring mutant mouse [9]. It produces a multiple-pass transmembrane protein (ANK) which regulates intracellular inorganic pyrophosphate (PPi) transportation from the cytoplasm to the extracellular space, thereby maintaining the PPi steady-state concentration, and thus possibly preventing increased calcification of the tissue [10]. Findings from previous studies show that mRNA and protein products of ANKH decrease with endplate degeneration [11].

Transforming growth factor $\beta 1$ (TGF- $\beta 1$ ) plays a significant role in regulating crystal deposition in endplate cartilage, and is able to induce PPi elaboration via TGF- $\beta 1$-induced $A N K H$ gene expression, thus being an important factor in the regulation of the calcification process [12].

Calcification involves the deposition of calcium phosphates, with alkaline phosphatase (ALP) playing an active role in initiating this process [13]. It hydrolyzes organic phosphates and PPi [14], yielding monophosphate ions $(\mathrm{Pi})$, which, in the presence of calcium ions, form hydroxyapatite crystals [15]. This process is, however, far more complicated, with ANKH (conjointly with ectoenzyme PC-1 - ENPP-1) deficiencies causing a possible decrease in $\mathrm{PPi}$ and osteopontin (OPN) levels [16].

However, most of the above-mentioned studies were performed on animal models or on a small number of human lumbar IVDs. None of them ventured to analyze the correlation between different PPi-associated proteins. Thus, the aim of this study was to clarify the relationship between the expression of ALP, ANK, ENPP-1, OPN and TGF- $\beta 1$ in the IVD, and cervical vertebral endplate calcification and degeneration.

\section{Material and methods}

\section{Material acquisition}

Sixty cervical IVDs were excised from 30 human cadavers (at the Department of Forensic Medicine, Jagiellonian University Medical College), using the anterior approach, not later than 48 hours post-mortem [17]. The material was excised in one block comprising vertebral bodies, IVDs, endplates and blood vessels supplying these structure, and wrapped in saline-soaked gauze, vacuum sealed to prevent dehydration, and kept at $4{ }^{\circ} \mathrm{C}$ until further processing. Excision started at the level of the lower half of the C4 vertebra and ended at the level of the upper half of the C6.

The study inclusion criterion was the ability to excise a section of the anterior spinal column (from the lower half of the $\mathrm{C} 4$ vertebra to the upper half of the C6), with the anterior and posterior longitudinal ligaments and blood vessels supplying the vertebrae. Study exclusion criteria were: 1 ) injury to the cervical spine, preventing excision of the required section; 2) previous cervical spine surgery; 3 ) receiving chemotherapy in the last 12 months; 4) previous radiation therapy to the perispinal region; 5) long-standing paralysis (6 or more months); 6) ankylosing spondylitis.

\section{Macroscopic and microscopic degeneration grading}

On the same day, each sample was unpacked from the vacuum-sealed container, and sectioned transversally at the middle of the $\mathrm{C} 5$ vertebral body. This produced two samples from each cadaver encompassing the IVD with both its endplates, surrounded from both ends by part of the vertebral bodies. Next each sample was sectioned along the midsagittal plane for macroscopic IVD degeneration scoring according to Thompson's classification [18]. Each cadaver was assessed by two of the authors, and the grade was averaged. Next, the samples were placed in a $10 \%$ solution of formaldehyde ( $\mathrm{pH}$ 7.4) for a minimum of 14 days for fixing.

Microscopic IVD and endplate degeneration was assessed using the Boos classification [5]. Each endplate and IVD was divided into 5 regions - anterior outer annulus (AO), anterior inner annulus (AI), nucleus pulposus (NP), posterior inner annulus (PI), and posterior outer annulus (PO). Tissue samples acquired from the midsagittal plane (of each of the 5 IVD regions) were decalcified, dehydrated, embedded in paraffin, sectioned at $4 \mu \mathrm{m}$, and stained with hematoxylin and eosin, Masson-Goldner trichrome and alcian blue-PAS (Department of Pathology, Jagiellonian University Medical College). Each sample was assessed and scored, using light microscopy (Nikon Eclipse 80i), by two observers, and the final score per sample was averaged.

The degree of endplate calcification was analyzed as the percentage of calcified tissue (red on Masson-Goldner trichrome staining). The fact of endplate calcification was verified on corresponding $\mathrm{HE}$ stained samples. The percentage of calcification was averaged for all examined endplate regions. 


\section{Immunohistochemistry}

For immunohistochemical localization, formalin-fixed tissue sections were treated for $10 \mathrm{~min}$ with $3 \% \mathrm{H}_{2} \mathrm{O}_{2}$. Heat-induced epitope retrieval was performed in EDTA ( $\mathrm{pH} 8.0) /$ citrate $\left(\mathrm{pH} \mathrm{6.0)}\right.$ ) at $98^{\circ} \mathrm{C}$ for 30 or $60 \mathrm{~min}$ depending on the antibody (as per the producer's recommendations). Sections were then incubated at room temperature with the following antibodies - ANK1 (1 : 50 concentration, Santa Cruz Biotechnology), SPP1 (1: 50 concentration, Lab Vision), alkaline phosphatase (1 : 50 concentration, Lab Vision), ENPP-1 (1 : 100 concentration, Santa Cruz Biotechnology), TGF- $\beta 1$ (1: 50 concentration, Abcam). After incubation the samples were washed in TBS (DAKO Corp.). For antigen-antibody visualization the Ultra Vision LP Values Detection System (Lab Vision) together with DAB (3,30-diaminobenzidine) (DAKO) was used according to the manufacturer's recommendations. Finally, sections were washed and then counterstained with Mayer's hematoxylin.

For each antibody and for each sample a negative control was processed. Negative controls were carried out by incubation in the absence of the primary antibody and always yielded negative results [19].

The intensity of the immunohistochemical reaction was measured using the following semi-quantitative grading scheme: $(-)$ no stained cells; $(+)$ 1-4 positive cells; $(++) 5-9$ positive cells; $(+++) \geq 10$ positive cells. Each sample was photographed and analyzed using Java ImageJ [20], by assessing 3 consecutive fields of view (FOV) (magnification $200 \times$ ) and calculating the average number of stained cells for each sample. Then the results from all the samples were averaged to obtain the final number of cells per FOV.

\section{Ethics}

The research protocol was approved by the Jagiellonian University Medical College Ethics Committee (registry number KBET/319/B/2012). The study was performed in accordance with the ethical standards laid down in the 1964 Declaration of Helsinki and its later amendments. The cadaver excision method was chosen so as not to destabilize the cadaver's spinal column.

\section{Statistical analysis}

Statistical analysis was conducted using Statistica 10.0 PL (StatSoft). Elements of descriptive statistics were used (mean, standard deviation percentage distribution). Differences between groups were tested with the unpaired Student's $t$ test or Mann-Whitney $U$ test as appropriate. To assess the correlation between scores, Pearson's correlation was used. Statistical significance was set at $\mathrm{p}<0.05$.

\section{Results}

The study group comprised 30 female and 30 male IVDs. The mean age \pm SD of the cadavers was 51.4 \pm 19.5 . The basic characteristics of the study group are presented in Table I.

Intervertebral disc degeneration, graded using Thompson's classification, significantly correlated with Boos's IVD degeneration score $(r=0.77$; $p<0.0001)$. Intervertebral disc and endplate degeneration, graded using Boos's score, also strongly correlated with each other $(r=0.96 ; p<0.0001)$. The percentage of endplate calcification significantly correlated with the degree of both endplate and IVD degeneration graded using Boos's score (both $\mathrm{r}=0.91$; $\mathrm{p}<0.0001$ ).

Table I. Basic characteristics of the study group

\begin{tabular}{lcccc}
\hline & $\begin{array}{c}\text { FeMALE } \\
(\mathrm{N}=30)\end{array}$ & $\begin{array}{c}\text { MALE } \\
(\mathrm{N}=30)\end{array}$ & $\begin{array}{c}\text { Total } \\
(\mathrm{N}=60)\end{array}$ & P-VALUE $^{A}$ \\
\hline Age (SD) & $52.8(19.8)$ & $50.0(19.4)$ & $51.4(19.5)$ & 0.57 \\
\hline IVD degeneration - Thompson classification (SD) & $2.6(1.3)$ & $3.2(1.3)$ & $2.9(1.3)$ & 0.08 \\
\hline IVD degeneration - Boos classification (SD) & $12.0(6.1)$ & $14.3(5.3)$ & $13.1(5.8)$ & 0.13 \\
\hline Endplate degeneration - Boos classification (SD) & $8.9(5.3)$ & $11.5(4.8)$ & $10.2(5.2)$ & 0.06 \\
\hline Endplate calcification [\%] (SD) & $28.4(25.1)$ & $44.1(26.0)$ & $36.2(26.5)$ & 0.02 \\
\hline IVD degeneration - Thompson classification vs. degree of endplate calcification $[\%](\mathrm{SD})$ & $6.2(2.6)$ & $6.7(0.6)$ & $6.3(2.1)$ & 0.31 \\
\hline Grade I & $13.2(2.8)$ & $17.7(1.9)$ & $14.8(3.3)$ & $<0.0001$ \\
\hline Grade II & $29.6(8.7)$ & $37.1(7.3)$ & $34.4(8.4)$ & 0.0006 \\
\hline Grade III & $53.3(6.9)$ & $61.6(4.8)$ & $57.9(7.0)$ & $<0.0001$ \\
\hline Grade IV & $77.3(8.5)$ & $79.1(2.8)$ & $78.5(5.2)$ & 0.28 \\
\hline Grade V
\end{tabular}

${ }^{A}$ for differences between females and males; SD - standard deviation; IVD - intervertebral disc 
Cadaver's age strongly correlated with both IVD degeneration (Thompson's and Boos's scores) and endplate degeneration (Boos score), as well as the averaged percentage of endplate calcification $(\mathrm{r}=0.76 ; \mathrm{r}=0.77 ; \mathrm{r}=0.73 ; \mathrm{r}=0.75$ respectively; $\mathrm{p}<0.0001)$.

Staining intensity of selected proteins per Thompson's degeneration grade for different IVD regions is presented in Tables II-VI. The intensity and number of stained cells per FOV markedly decreased, for the majority of analyzed proteins (ANK, ENPP-1, and TGF- $\beta 1$ ), with the grade of IVD degeneration, regardless of the analyzed region. This was not true only for ALP, which demonstrated an increasing trend corresponding to the degree of IVD degeneration. The expression of OPN was low throughout

Table II. Staining intensity of selected proteins per Thompson's degeneration grade for the anterior outer annulus of the intervertebral disc

\begin{tabular}{|c|c|c|c|c|c|}
\hline $\begin{array}{l}\text { ANTERIOR OUTER } \\
\text { ANNULUS (AO) }\end{array}$ & $\begin{array}{c}\text { THOMPSON } \\
\text { GRADE I } \\
(\mathrm{N}=9)\end{array}$ & $\begin{array}{c}\text { THOMPSON } \\
\text { GRADE II } \\
(\mathrm{N}=17)\end{array}$ & $\begin{array}{l}\text { THOMPSON } \\
\text { GRADE III } \\
(\mathrm{N}=14)\end{array}$ & $\begin{array}{c}\text { THOMPSON } \\
\text { GRADE IV } \\
(\mathrm{N}=9)\end{array}$ & $\begin{array}{c}\text { THOMPSON } \\
\text { GRADE V } \\
(\mathrm{N}=11)\end{array}$ \\
\hline ALP & + & ++ & ++ & +++ & + \\
\hline ANK & ++ & ++ & + & + & + \\
\hline ENPP-1 & +++ & +++ & ++ & + & + \\
\hline OPN & - & + & + & ++ & + \\
\hline TGF- $\beta 1$ & +++ & ++ & + & + & - \\
\hline $\begin{array}{l}\text { Grading scheme: (-) no } \\
\text { ALP - alkaline phospha } \\
\text { Each sample was analyz } \\
\text { Then the results from all }\end{array}$ & $\begin{array}{l}l s ;(+) 1-4 \text { posit } \\
K \text { - ankyrin; EN } \\
\text { sing } 3 \text { consecutive } \\
\text { es were averaged } t\end{array}$ & $\begin{array}{l}++ \text { ) 5-9 positive } \\
\text { oenzyme PC-1; } \\
\text { ew (FOV) (magn } \\
\text { e final number of }\end{array}$ & $\begin{array}{l}++) \geq 10 \text { positil } \\
\text { opontin; } T G F-\beta 1 \\
O O \times) \text { and calcul } \\
O V\end{array}$ & $\begin{array}{l}\text { rming growth fa } \\
\text { average number }\end{array}$ & Is for each sample \\
\hline
\end{tabular}

Table III. Staining intensity of selected proteins per Thompson's degeneration grade for the anterior inner annulus of the intervertebral disc

\begin{tabular}{|c|c|c|c|c|c|}
\hline $\begin{array}{l}\text { ANTERIOR INNER } \\
\text { ANNULUS (AI) }\end{array}$ & $\begin{array}{c}\text { THOMPSON } \\
\text { GRADE I } \\
(\mathrm{N}=9)\end{array}$ & $\begin{array}{c}\text { THOMPSON } \\
\text { GRADE II } \\
(\mathrm{N}=17)\end{array}$ & $\begin{array}{l}\text { THOMPSON } \\
\text { GRADE III } \\
(\mathrm{N}=14)\end{array}$ & $\begin{array}{c}\text { THOMPSON } \\
\text { GRADE IV } \\
(\mathrm{N}=9)\end{array}$ & $\begin{array}{c}\text { THOMPSON } \\
\text { GRADE V } \\
(\mathrm{N}=11)\end{array}$ \\
\hline ALP & + & ++ & +++ & +++ & + \\
\hline ANK & +++ & +++ & ++ & + & + \\
\hline ENPP-1 & ++ & +++ & ++ & - & - \\
\hline OPN & - & + & ++ & + & + \\
\hline TGF- $\beta 1$ & +++ & +++ & ++ & + & + \\
\hline
\end{tabular}

Table IV. Staining intensity of selected proteins per Thompson's degeneration grade for the nucleus pulposus region of the intervertebral disc

\begin{tabular}{|c|c|c|c|c|c|}
\hline $\begin{array}{l}\text { NuClEUS } \\
\text { PULPOSUS (NP) }\end{array}$ & $\begin{array}{c}\text { THOMPSON } \\
\text { GRADE I } \\
(\mathrm{N}=9) \\
\end{array}$ & $\begin{array}{c}\text { THOMPSON } \\
\text { GRADE II } \\
(\mathrm{N}=17) \\
\end{array}$ & $\begin{array}{l}\text { THOMPSON } \\
\text { GRADE III } \\
(\mathrm{N}=14)\end{array}$ & $\begin{array}{c}\text { THOMPSON } \\
\text { GRADE IV } \\
(\mathrm{N}=9)\end{array}$ & $\begin{array}{c}\text { THOMPSON } \\
\text { GRADE V } \\
(\mathrm{N}=11)\end{array}$ \\
\hline ALP & - & + & ++ & ++ & + \\
\hline ANK & +++ & ++ & + & + & - \\
\hline ENPP-1 & +++ & +++ & ++ & + & - \\
\hline OPN & + & + & + & + & + \\
\hline TGF- $\beta 1$ & ++ & ++ & + & + & + \\
\hline
\end{tabular}


Table V. Staining intensity of selected proteins per Thompson's degeneration grade for the posterior inner annulus of the intervertebral disc

\begin{tabular}{|c|c|c|c|c|c|}
\hline $\begin{array}{l}\text { POSTERIOR INNER } \\
\text { ANNULUS (PI) }\end{array}$ & $\begin{array}{c}\text { THOMPSON } \\
\text { GRADE I } \\
(\mathrm{N}=9)\end{array}$ & $\begin{array}{c}\text { THOMPSON } \\
\text { GRADE II } \\
(\mathrm{N}=17)\end{array}$ & $\begin{array}{l}\text { THOMPSON } \\
\text { GRADE III } \\
(\mathrm{N}=14)\end{array}$ & $\begin{array}{c}\text { THOMPSON } \\
\text { GRADE IV } \\
(\mathrm{N}=9)\end{array}$ & $\begin{array}{c}\text { THOMPSON } \\
\text { GRADE V } \\
(\mathrm{N}=11)\end{array}$ \\
\hline ALP & + & + & +++ & ++ & + \\
\hline ANK & ++ & ++ & + & - & - \\
\hline ENPP-1 & +++ & +++ & ++ & + & - \\
\hline OPN & + & - & ++ & + & - \\
\hline TGF- $\beta 1$ & +++ & ++ & + & + & + \\
\hline
\end{tabular}

Table VI. Staining intensity of selected proteins per Thompson's degeneration grade for the posterior outer annulus of the intervertebral disc

\begin{tabular}{|c|c|c|c|c|c|}
\hline $\begin{array}{l}\text { Posterior OUTER } \\
\text { ANNULUS (PO) }\end{array}$ & $\begin{array}{c}\text { THOMPSON } \\
\text { GRADE I } \\
(\mathrm{N}=9)\end{array}$ & $\begin{array}{c}\text { THOMPSON } \\
\text { GRADE II } \\
(\mathrm{N}=17)\end{array}$ & $\begin{array}{l}\text { THOMPSON } \\
\text { GRADE III } \\
(\mathrm{N}=14)\end{array}$ & $\begin{array}{c}\text { THOMPSON } \\
\text { GRADE IV } \\
(\mathrm{N}=9)\end{array}$ & $\begin{array}{c}\text { THOMPSON } \\
\text { GRADE V } \\
(\mathrm{N}=11)\end{array}$ \\
\hline ALP & + & ++ & +++ & ++ & ++ \\
\hline ANK & ++ & ++ & + & + & + \\
\hline ENPP-1 & ++ & ++ & + & + & - \\
\hline OPN & - & + & + & - & + \\
\hline TGF- $\beta 1$ & ++ & ++ & + & + & - \\
\hline
\end{tabular}

all analyzed regions, regardless of the degree of IVD degeneration.

Figure 1 presents selected intervertebral disc regions (all from the annulus fibrosus) stained (immunohistochemistry) for ankyrin, and their corresponding endplate zones stained with Masson's trichrome. A distinct negative correlation can be seen between the expression of ankyrin in the IVD and the degree of calcification of the vertebral endplate.

\section{Discussion}

The aim of this study was to clarify the relationship between the expression of ALP, ANK, ENPP-1, OPN and TGF- $\beta 1$ in the IVD, and cervical vertebral endplate calcification and degeneration. The most significant finding of this study is the fact that, for the first time in a large group of cervical IVDs, it was possible to confirm that there exists a strong relationship between decreased expression of ANK, ENPP-1, and TGF- $\beta 1$ in the IVD and an increase in IVD degeneration and endplate degeneration and calcification. This finding was probably most evident for ANK and TGF- $\beta 1$, as both proteins are strongly intertwined with each other in the process of calcification [12]. ALP, as expected, was expressed more intensively in IVDs with a higher degree of calcification, as ALP is a marker of ongoing mineral deposition [14].

It is still not clear whether calcification is the cause or the effect of IVD and/or endplate degeneration. Some authors cautiously state that both processes exist simultaneously and are strongly associated with each other [21]. However, the results of our previous study (results not yet published) indicated that endplate calcification is the cause, rather than the effect of a fall in nutrient transport, as it starts in the well-vascularized center of the endplate, and not in the outer regions where the number of endplate openings (marrow contact channels) is lower. Unfortunately, definitive conclusions have to be withheld until "cause and effect" studies provide further data.

This study has demonstrated that there exists a strong correlation between the degree of endplate and IVD degeneration and the intensity of endplate calcification, as well as the age of the cadaver. The latter has already been shown in previous studies [22, 23 ], showing at the same time that currently it is 

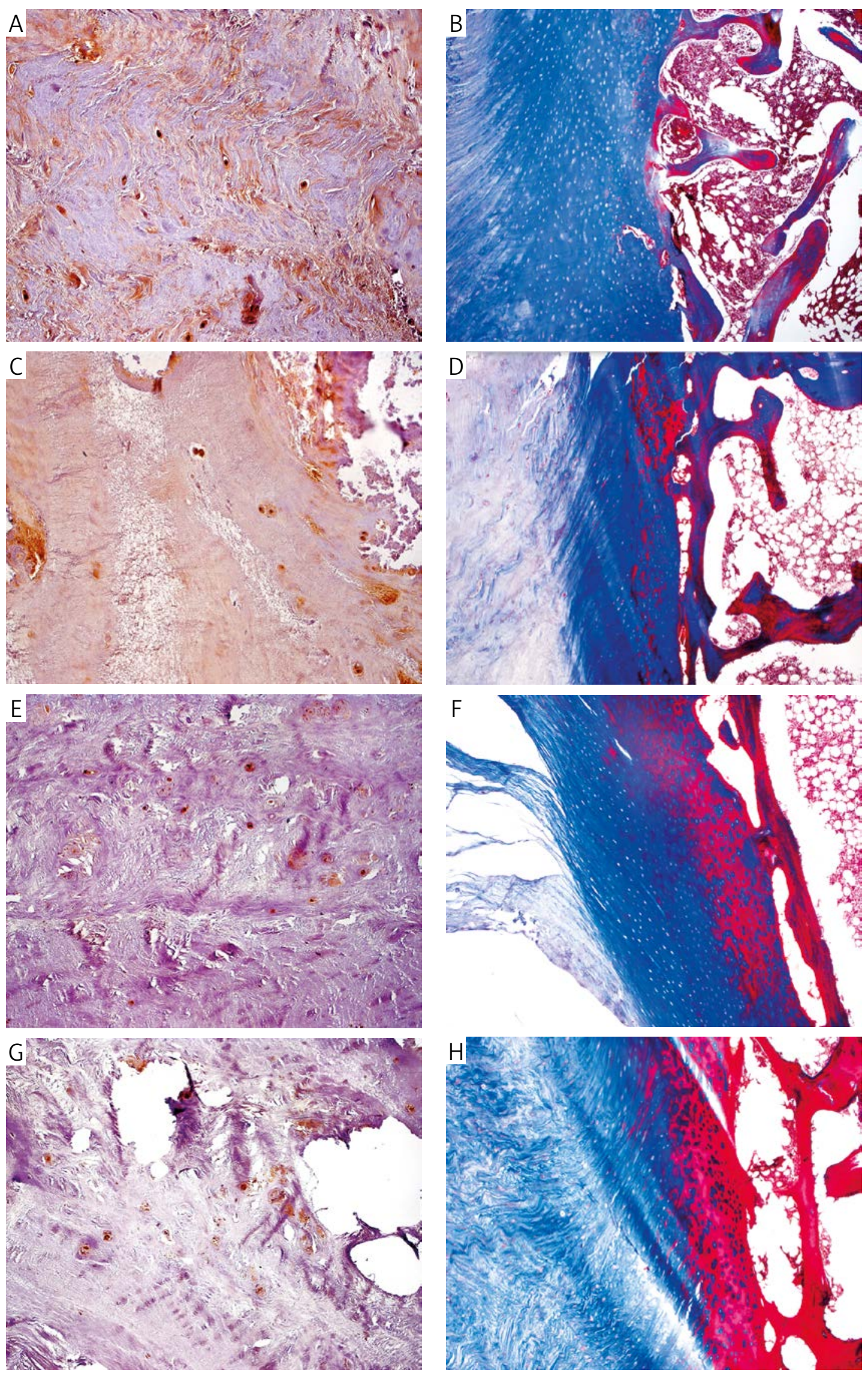

Fig. 1. Selected intervertebral disc regions (annulus fibrosus) stained (immunohistochemistry) for ankyrin, and their corresponding endplate zones stained with Masson's trichrome. A, C, E, G) Immunohistochemistry staining for ankyrin. B, D, F, H) Masson's trichrome staining (red indicates calcification) 


\begin{tabular}{|c|c|c|c|c|}
\hline FigURE LETTERING & Patient's age & $\begin{array}{c}\text { THOMPSON's IVD } \\
\text { DEGENERATION GRADE }\end{array}$ & $\begin{array}{c}\text { BoOs IVD } \\
\text { DEGENERATION GRADE }\end{array}$ & $\begin{array}{c}\text { BOOS ENDPLATE } \\
\text { DEGENERATION GRADE }\end{array}$ \\
\hline$A \& B$ & 22 & I & 2 & 2 \\
\hline$C \& D$ & 37 & II & 7 & 5 \\
\hline $\mathrm{E} \& \mathrm{~F}$ & 54 & III & 13 & 10 \\
\hline$G \& H$ & 82 & V & 19 & 17 \\
\hline
\end{tabular}

Fig. 1. Cont.

impossible to differentiate between changes related purely to ageing from those occurring due to pathological degeneration. This has also been shown to be true for the cervical spine, where in a longitudinal study no other factor except for age was related to the progression of degeneration [24]. The correlation between IVD calcification and degeneration has also been shown before [25], but never so clearly for the relationship between endplate calcification and IVD degeneration. Our study also confirms that the first calcifications in the endplate can be seen as early as in the third decade of life [25]. However, in this young age group the occurrence of calcifications is rather rare, with the majority being found in the cervical or thoracic spine - sites not so prone to degeneration as the lumbosacral region $[25,26]$. A study by Rutges et al. [25] showed that some of the calcifications found in the IVD are located around viable cells, suggesting the origin of calcium salt production, which may result from end stage hypertrophic differentiation. However, Rutges et al. [25] found that in the nucleus pulposus of young patients, calcifications were always associated with notochordal cells, indicating a different mechanism underlying calcification probably associated with the activity of Runx2, ALP and osteoprotegerin.

The differences in the staining intensity found between IVD regions (nucleus pulposus vs. different regions of the annulus fibrosus) may possibly originate from the fact that endplate cartilage and annulus fibrosus cells are derived from mesenchymal cells, while cells of the nucleus pulpous are derived from notochordal cells [27].

The expression of ANK, ENPP-1, and TGF- $\beta 1$ markedly decreased with the grade of IVD degeneration. ANK is a transmembrane protein responsible for regulating the intra- and extracellular transport of PPi [9], and is considered a significant "anti-calcification" protein [11]. It has been mentioned [9] that when the ANK channel protein fails in its function, then calcium pyrophosphate dehydrate is deposited in the cartilage. The current study confirms earlier findings from animal models that ANK protein expression decreases with degeneration [10], suggesting its significant role in the mechanism of pathological calcification. It has been reported that TGF- $\beta 1$ plays an important role in regulating the expression of
ANK in chondrocytes, through Ras/Raf-1/ERK and $\mathrm{Ca}^{2+}$-dependent PKC signal-regulated kinase pathways [12]. Also cyclic mechanical tension applied to cultured endplate chondrocytes increased the expression of both ANK and TGF- $\beta 1$ [8]. What is more, ANK protein expression increases in a dose-dependent manner when treated with TGF- $\beta 1$ [8]. All of the above facts would explain the strong association between ANK and TGF- $\beta 1$ expression found in our study. The somewhat weaker, but still significant, association found in this study between ANK, ENPP-1, and TGF- $\beta 1$ expression further proves that ANK is more sensitive to TGF- $\beta 1$ than ENPP-1 [12].

The reason for poor expression of OPN, both in the vertebral endplate and the IVD, is not clear. We expected to see increasing expression of OPN correlating with the degree of degeneration and endplate calcification, as OPN plays an important role in mineralization [28]. The obtained results stand in opposition to the calcification mechanisms discovered in tendons and blood vessels, where hydroxyapatite deposition is strongly related to osteopontin, type $\mathrm{X}$ collagen, and osteonectin [29, 30]. It is probable that the fact of the IVD being an avascular structure plays an important role in modulating the process of calcification [28].

ALP expression was found to increase with the progression of endplate and IVD degeneration and calcification, with the exception of Thompson grade V IVDs. This finding suggests that ALP is involved in extracellular mineralization - more likely so as the localization of ALP activity coincided with the location where many of the calcifications were found. ALP is one of the most important proteins in the process of calcification, and its increase in more calcified IVDs was expected. However, it is not only ALP that could be responsible for increased IVD calcification. Primary annulus fibrosus cells are also likely responsible for this process in the IVD [31]. The significant decrease of ALP expression in the most degenerated IVDs is most likely caused by the large degree of cell death found in Thompson grade $\mathrm{V}$ cadavers.

In conclusion, this study has pointed out the important and intertwined role of ANK, TGF- $\beta 1$, ENPP-1, and OPN in the process of IVD and endplate degeneration and calcification. Modulating the expression of the above-mentioned proteins, especial- 
ly ANK and TGF- $\beta 1$, may be a new way to prevent degeneration and calcification of the IVD. Further studies are still needed to elucidate the cause and effect relationship between endplate calcification and IVD degeneration.

\section{The authors declare no conflict of interest.}

The authors want to thank Mr. Krzysztof Skomski for his excellent microphotographs. This study was funded by the National Science Center - Poland under grant number DEC-2012/07/N/NZ5/00078. Krzysztof A. Tomaszewski received a scholarship to prepare his $P h D$ thesis from the National Science Center-Poland under award number DEC-2013/08/T/NZ5/00020.

\section{References}

1. Vos T, Flaxman AD, Naghavi M, et al. Years lived with disability (YLDs) for 1160 sequelae of 289 diseases and injuries 19902010: a systematic analysis for the Global Burden of Disease Study 2010. Lancet 2012; 380: 2163-2196.

2. Froud R, Patterson S, Eldridge S, et al. A systematic review and meta-synthesis of the impact of low back pain on people's lives. BMC Musculoskelet Disord 2014; 15: 50.

3. Maniadakis N, Gray A. The economic burden of back pain in the UK. Pain 2000; 84: 95-103.

4. Raj PP. Intervertebral disc: anatomy-physiology-pathophysiology-treatment. Pain Pract 2008; 8: 18-44.

5. Boos N, Weissbach S, Rohrbach $\mathrm{H}$, et al. Classification of age-related changes in lumbar intervertebral discs: 2002 Volvo Award in basic science. Spine 2002; 27: 2631-2644.

6 . Moore RJ. The vertebral endplate: disc degeneration, disc regeneration. Eur Spine J 2006; 15 Suppl 3: S333-337.

7. van der Werf M, Lezuo P, Maissen O, et al. Inhibition of vertebral endplate perfusion results in decreased intervertebral disc intranuclear diffusive transport. J Anat 2007; 211: 769-774.

8. Xu H, Zhang X, Wang H, et al. Continuous cyclic mechanical tension increases ank expression in endplate chondrocytes through the TGF- $\beta 1$ and p38 pathway. Eur J Histochem 2013; 57: e28

9.Zaka R, Williams CJ. Role of the progressive ankylosis gene in cartilage mineralization. Curr Opin Rheumatol 2006; 18 : 181-186.

10. Xu HG, Hu CJ, Wang H, et al. Effects of mechanical strain on ANK, ENPP1 and TGF- $\beta 1$ expression in rat endplate chondrocytes in vitro. Mol Med Rep 2011; 4: 831-835.

11. Xu HG, Song JX, Cheng JF, et al. JNK phosphorylation promotes degeneration of cervical endplate chondrocytes through down-regulation of the expression of ANK in humans. Chin Med J (Engl) 2013; 126: 2067-2073.

12. Cailotto F, Bianchi A, Sebillaud S, et al. Inorganic pyrophosphate generation by transforming growth factor-beta- 1 is mainly dependent on ANK induction by Ras/Raf-1/extracellular signal-regulated kinase pathways in chondrocytes. Arthritis Res Ther 2007; 9: R122.

13. Miller GJ, DeMarzo AM. Ultrastructural localization of matrix vesicles and alkaline phosphatase in the Swarm rat chondrosarcoma: their role in cartilage calcification. Bone 1988; 9: 235-241.

14. Hristova GI, Jarzem P, Ouellet JA, et al. Calcification in human intervertebral disc degeneration and scoliosis. J Orthop Res 2011; 29: 1888-1895.

15. Anderson HC, Sipe JB, Hessle L, et al. Impaired calcification around matrix vesicles of growth plate and bone in alkaline phosphatase-deficient mice. Am J Pathol 2004; 164: 841-847.
16. Harmey D, Hessle L, Narisawa S, et al. Concerted regulation of inorganic pyrophosphate and osteopontin by akp2, enpp1, and ank: an integrated model of the pathogenesis of mineralization disorders. Am J Pathol 2004; 164: 1199-1209.

17. Le Maitre CL, Freemont AJ, Hoyland JA. The role of interleukin-1 in the pathogenesis of human intervertebral disc degeneration. Arthritis Res Ther 2005; 7: R732-745.

18. Thompson JP, Pearce RH, Schechter MT, et al. Preliminary evaluation of a scheme for grading the gross morphology of the human intervertebral disc. Spine 1990; 15: 411-415.

19. Pyziak L, Stasikowska-Kanicka O, Danilewicz M, Wagrowska-Danilewicz M. Immunohistochemical analysis of mast cell infiltrates and microvessel density in oral squamous cell carcinoma. Pol J Pathol 2013; 64: 276-280.

20. Mizia E, Tomaszewski KA, Lis GJ, et al. The use of computer-assisted image analysis in measuring the histological structure of the human median nerve. Folia Morphol (Warsz) 2012; 71: 82-85.

21. Gruber HE, Ashraf N, Kilburn J, et al. Vertebral endplate architecture and vascularization: application of microcomputerized tomography, a vascular tracer, and immunocytochemistry in analyses of disc degeneration in the aging sand rat. Spine 2005; 30: 2593-2600.

22. Sowa G, Vadalà G, Studer R, et al. Characterization of intervertebral disc aging: longitudinal analysis of a rabbit model by magnetic resonance imaging, histology, and gene expression. Spine 2008; 33: 1821-1828.

23. Miller JA, Schmatz C, Schultz AB. Lumbar disc degeneration: correlation with age, sex, and spine level in 600 autopsy specimens. Spine 1988; 13: 173-178.

24. Okada E, Matsumoto M, Ichihara D, et al. Aging of the cervical spine in healthy volunteers: a 10-year longitudinal magnetic resonance imaging study. Spine 2009; 34: 706-712.

25. Rutges JP, Duit RA, Kummer JA, et al. Hypertrophic differentiation and calcification during intervertebral disc degeneration. Osteoarthritis Cartilage 2010; 18: 1487-1495.

26. Dai LY, Ye H, Qian QR. The natural history of cervical disc calcification in children. J Bone Joint Surg Am 2004; 86: 1467-1472.

27. Sive JI, Baird P, Jeziorsk M, et al. Expression of chondrocyte markers by cells of normal and degenerate intervertebral discs. Mol Pathol 2002; 55: 91-97.

28. Melrose J, Burkhardt D, Taylor TK, et al. Calcification in the ovine intervertebral disc: a model of hydroxyapatite deposition disease. Eur Spine J 2009; 18: 479-489.

29. Takeuchi E, Sugamoto K, Nakase T, et al. Localization and expression of osteopontin in the rotator cuff tendons in patients with calcifying tendinitis. Virchows Arch 2001; 438: 612-617.

30. Moe SM, Chen NX. Pathophysiology of vascular calcification in chronic kidney disease. Circ Res 2004; 95: 560-567.

31. Nosikova Y, Santerre JP, Grynpas MD, Kandel RA. Annulus fibrosus cells can induce mineralization: an in vitro study. Spine J 2013; 13: 443-453.

\section{Address for correspondence}

\section{Krzysztof A. Tomaszewski}

Department of Anatomy

Jagiellonian University Medical College

Kopernika 12

31-034 Krakow, Poland

tel./fax +48124229511

e-mail: krtomaszewski@gmail.com 